\title{
FISIEKE AKTIWITEIT EN UITBRANDING SE VERBAND MET DIE GESONDHEIDSTATUS VAN VROULIKE BESTUURSLUI
}

\author{
LI DREYER \\ Skool vir Biokinetika, Rekreasie en Sportwetenskap \\ Potchefstroomse Universiteit vir Christelike Hö̈r Onderwys \\ EC LE ROUX \\ Biokinetikus in privaatpraktyk \\ Brits, Republiek van Suid Afrika \\ JM LOOTS \\ GL STRYDOM \\ Suid Afrikaanse Biokinetika \\ Vereniging
}

\begin{abstract}
The relationship of physical activity and burnout with the health status of female executives.The purpose of this study was, firstly, to investigate the relationship between burnout and health status. Secondly, the purpose was to determine the effect of physical activity on the possible burnout-health-relationship. The subjects included 278 female executives. The results indicated that low burnout scores were concomitant with a good health status. The results also indicated that physical activity had no influence on the relationship between burnout and health status. Burnout, on the other hand, showed a negative relationship with health status, independent of the level of participation in physical activity.
\end{abstract}

\section{OPSOMMING}

Die doel van hierdie studie was eerstens om die verband tussen uitbranding en gesondheidstatus by ' $\mathrm{n}$ groep vroulike bestuurslui te bestudeer. Tweedens is ondersoek of deelname aan fisieke aktiwiteit enige invloed het op die moontlike uitbrandings-gesondheidstatus-verwantskap. Die proefpersone was 278 vroulike bestuurslui. Uitbranding toon 'n direkte en statisties betekenisvolle $(\mathrm{p}(0.05)$ verband met gesondheidstatus. Hoe laer die uitbrandingspunt, hoe beter was die gesondheidstatus van die respondente. Uitbranding toon verder in die tweerigtingvariansie-analise onafhanklik van deelname aan fisieke aktiwiteit ' $n$ statisties betekenisvolle $(\mathrm{p}(0.05)$ verband met gesondheidstatus. In kontras hiermee het fisieke aktiwiteit by al drie die uitbrandingsgroepe geen verband met gesondheidstatus vertoon nie.

\section{SYNOPSIS}

Various stress models or adaptations to stress models can be found in the research literature. The one most commonly used is the general adaptation syndrome model of Selye (1956) which states that stress adaptation has three distinct phases.

The first phase is the alarm reaction that starts the moment the individual becomes aware of the stressor. This reaction causes the secretion of adrenaline and other stress hormones, which prepares the body for flight or fight. The second phase is the stage of resistance where the individual's ability to perform and resist the stressor rises above normal because of the secretion of stress hormones like cortisol. This stage can continue for a long time but will eventually, if continued long enough, lead to the third stage namely, the stage of exhaustion. During this stage the individual reaches a stage where his/her resources are overtaxed and his ability to resist starts to decline. The individual's ability to perform decreases which leads to more stress and still lower productivity. This later stage of the general adaptation process is also normally associated with behavioural and cognitive problems like aggression, an inability to concentrate, frustration, short temperedness, and the development of all sorts of physical problems. This stage eventually leads to cognitive, emotional and physical exhaustion or burnout.

The "burntout" person tends to detach him/herself from the people (s)he has to work with, by losing concern, by intellectualising, by becoming cynical about work, and even by becoming derogatory and contemptuous of the very people (s) he is supposed to help or manage.

Versoeke vir afskrifte moet gerig aan: LI Dreyer, Bachelor of Human Performance Programme, Universal College of Learning, Palmerston North, 5301, New Zealand
It is well known that physical exercise can be used as method to restore the homeostasis and counter the negative physiological effect of stress. Burnout is, however, a stage where the individual has reached a point of exhaustion and any further demands on the system tends to worsen the situation. The mechanics through which physical exercise improves ability is known as a process of breakdown and recovery. The physical exercise places demands on the structure or body that the body is not used to, and the body adapts by becoming stronger or better. Physical exercise also stimulates the secretion of hormones like endorphins that causes the individual to feel better. In the case of psychological stress, physical exercise in all probability restores the homeostasis because it provides exactly that for which the body was prepared, namely activity (fight or flight). Little is known about the exact mechanics by which activity restores the internal homeostasis in the case of psychological stress. The question now arises if physical exercise can restore the internal homeostasis in a system that is already overtaxed and that has reached a point of exhaustion. Burnout and stress is also, and maybe more spesifically, a product of philosophical issues like values, norms, rules and worldview. It is improbable that physical exercise will change an individual's worldview and it, therefore, remains an open question as to whether exercise will have health benefits for people in a state of physical, cognitive and emotional exhaustion. Little is also known about the prevalence of burnout amongst female executives in South Africa.

The purpose of this study was, therefore, firstly to investigate the relationship between burnout and the health status in a cohort of female executives. Secondly, the study aimed at determining the effect of physical activity on the possible negative burnout-healthrelationship.

Two hundred and seventy eight (278) female executives between the ages of 20 and 60 years participated in this study. The 
data was sampled in companies located in all the provinces in South Africa as part of the SANGALA-project. The SANGALA-project is a national project that aims at increasing participation in sport and physical activity amongst all population groups. Corporate SANGALA is specifically designed to target executives and is run/managed by the South African Biokinetic Association (SABA). The SABA uses biokineticists in private practice located in the various provinces to sample the data. The questionnaires and the data were analysed at the Potchefstroom University for Christian Higher Education. The data sampling process started in August 1999 and information of all female executives sampled up to May 2001 were included in this study.

Participation in physical activity was measured with the Physical Activity Index of Sharkey (1984) which quantifies the exercise principles: intensity, frequency and duration into a score that reflects true quality of participation in physical activity. The Seriousness of Illness Rating Scale (IRS) of Wyler, Masuda and Holmes (1968) was used to measure health status. The Seriousness of Illness Survey is a self-reported checklist of 126 commonly recognized physical and mental diseases. A general severity weight is applied to each disorder that reflects prognosis, duration, threat to life, degree of disability, and degree of discomfort. Burnout was determined by using the Pines Burnout-Scale (Pines, Aronson \& Kafry, 1981). It is a 21-item questionnaire that measures physical, cognitive and emotional exhaustion. Relationships between these scales/questionnaires were studied by using one-way and two-way analyses of variance.

It was found that $44.8 \%$ of the female executives in this study exhibited no or little burnout. Moderate burnout and serious burnout was prevalent amongst respectively $44.0 \%$ and $11.2 \%$ of the respondents. Moderate and serious burnout was, therefore, found among $55.2 \%$ of the female executives participating in this study. The one-way analysis of variance indicated that burnout showed a direct and statistically significant $(p(0.05)$ relationship with health, as measured with the Seriousness of Illness Rating Scale. Respondents with no or little burnout were statistically significantly healthier than respondents with moderate and serious burnout. The relationship between burnout and health was also linear reflected in the fact that respondents with moderate burnout were also statistically significantly healthier than the respondents with serious burnout. The results of the two-way analysis of variance indicated that participation in physical activity had no or little effect on the negative burnout-health-relationship. Physically inactive respondents with low burnout were statistically significantly healthier than highly active respondents with moderate and serious burnout.

The results of this study, therefore, indicated that physical activity was not concomitant with better health among respondents that were in a stress-induced state of physical, emotional and cognitive exhaustion.

Spanning kan ' $n$ betekenisvolle effek op die kommunikasie- en besluitnemingsvermoëns van bestuurslui hê, aldus Dickman (1988) en Robbins, Powers en Burgess (1991). Dit is ook goed bekend dat stres ' $n$ negatiewe uitwerking op lewenstyl en gesondheid van die individu het (Robbins et al., 1991; Dreyer, 1996). Strümpfer (1982) is van mening dat stres nie noodwendig altyd sleg is nie en dat daar onderskei kan word tussen goeie stres (eustress) en skadelike stres (dystress). Die verskil lê volgens Strümpfer (1982) in hoe die individu dit wat hy ervaar, evalueer en interpreteer. Die hantering van stres kan volgens navorsers (Dickman, 1988; Robbins et al., 1991; Strümpfer, 1982; in drie fases verdeel word. Hierdie drie fases is omskryf deur Selye (1956) en hy verwys daarna as die algemene aanpas-singsindroom.

Die eerste fase is die sogenaamde alarmreaksie en begin sodra die individu bewus word van die stressor. Die alarmreaksie gee aanleiding tot die afskeiding van adrenalien en ander streshormone wat sekere fisiologiese reaksies soos die toename in harttempo, asemhalingstempo, spierspanning, spierkrag, metaboliese snelheid en bloedvloei na die spiere, veroorsaak. Hierdie veranderinge het alles te doen met die sogenaamde veg-of-vlug-respons. Die tweede fase is die weerstandsfase waartydens die persoon as gevolg van die afskeiding van die streshormone oor verhoogde fisieke en intellektuele vermoëns beskik. Hierdie fase kan vir 'n lang tydperk duur, maar lei tot die derde fase, naamlik dié van uitputting. As die individu hierdie stadium bereik, verswak sy intellektuele vermoëns, met 'n gevolglike afname in produktiwiteit en nog hoër stresvlakke. Dit lei uiteindelik tot uitbranding en gaan gewoonlik gepaard met stressimptome asook gedrags- en kognitiewe afwykings. Tipiese stressimptome en gedragsafwykings wat in dié fase voorkom, sluit in aspekte soos:

- 'n oormatige geneigdheid om te kompeteer

- woede, vyandigheid en aggressie

- gevoelens van hulpeloosheid en selfbejammering

- onvermoë om te ontspan

- gebrek aan eetlus

- spanningshoofpyne

- maagsere, sooibrand en hardlywigheid

- pitswere, karbonkels en ekseem (Ardell, 1986; Dreyer, 1996; Dickman, 1988; Robbins et al., 1991).

Die toerie is dan ook dat mense wat die uitputtingsfase bereik en aan uitbranding ly bogenoemde simptome vertoon en meer geneig is om siek te word (Dreyer, 1996). Stres en lewenstyl is faktore wat bewustelik verander kan word om te lei tot verbetering van gesondheid (Dreyer, 1996; Dickman, 1988). Verskeie studies het in dié verband dan ook verbande tussen stres en aspekte soos werksafwesighede en gesondheidskostes aangetoon (Baun, Bernacki \& Tsai; 1986; Beehr, 1978; Bly, Jones \& Richardson, 1986). Min studies het egter na die invloed van fisieke aktiwiteit op uitbranding se verband met siekte of gesondheid gekyk. Veral oor vroulike bestuurslui is daar feitlik geen navorsing beskikbaar nie.

Dit is bekend dat fisieke aktiwiteit as ' $\mathrm{n}$ teenvoeter vir stres gebruik kan word (Aldana, Sutton, Jacobson \& Quirk, 1996; Shephard, 1997). Fisieke aktiwiteit se verband met gesondheid is ook al goed gedokumenteer en by herhaling in navorsingstudies bevestig (Blair et al., 1996; Bouchard \& Despres, 1995; Massie, 1992; Plowman, 1992). Dit is egter onduidelik of fisieke aktiwiteit met beter gesondheidsprofiele gepaard sal gaan by respondente wat aan uitbranding ly. Die vrae wat derhalwe met die navorsing beantwoord wil word, is of uitbranding enige verband met gesondheidstatus by vroulike bestuurslui toon. Tweedens ontstaan die vraag of fisieke aktiwiteit enige effek het op die moontlike verband wat uitbranding met gesondheidstatus het. Antwoorde hierop sal ' $n$ aanduiding verskaf van uitbranding se verband met gesondheidstatus. Dit sal ook aandui of vroulike bestuurslui wat aan uitbranding ly en fisiek aktief is, oor ' $n$ beter staat van gesondheid beskik as vrouens wat fisiek onaktief is.

\section{METODE VAN ONDERSOEK}

\section{Proefpersone}

Twee honderd agt en sewentig vroulike bestuurslui tussen die ouderdom twintig en sestig (20-60 jaar) wat op ewekansig beskikbaarheidswyse verkry is, is vir die doel van die studie gebruik. Die inligting vir die studie is regoor Suid-Afrika by maatskappye ingesamel (SANGALA-projek). Die SANGALAprojek is ' $n$ dwarsdeursnit-korrelerend-beskrywende navorsingstudie wat die verbande tussen verskeie veranderlikes vir ' $\mathrm{n}$ spesifieke populasie ondersoek. Die projek is ' $\mathrm{n}$ 
nasionale projek wat ten doel het om sportbeoefening en deelname aan fisieke en vryetydaktiwiteite te bevorder. "Corporate"-SANGALA is spesifiek gerig op bestuurslui en is ' $\mathrm{n}$ projek wat deur die Suid-Afrikaanse Biokinetikavereniging hanteer word. Genoemde vereniging taak biokinetici regoor die land om inligting by maatskappye in te samel en gesondheidsopvoeding te doen. Die projek is in 1998 geloods. Die data insamelingsproses het in Augustus 1999 begin en inligting van al die blanke vroulike middel- en topvlakbestuurslui wat die vraelyste voltooi het tot die einde van Mei 2001, is gebruik.

\section{Meetinstrumente}

\section{Fisieke aktiwiteitsindeks}

Die fisieke aktiwiteitsindeks van die respondente is bepaal deur gebruik te maak van die metode soos deur Sharkey (1984) aangebied. Die indeks van Sharkey is reeds in verskeie studies (Dreyer, 1991; Jordaan, 1998; Rabie, 1999; Van der Merwe, 1995) gebruik om respondente se deelname aan fisieke aktiwiteit te gradeer. Volgens díe metode word deelname aan fisieke aktiwiteit as indeks uitgedruk deur numeriese waardes aan die inoefeningsvereistes, naamlik intensiteit, duur en frekwensie van deelname toe te ken en hierdie drie waardes met mekaar te vermenigvuldig.

\section{Gesondheidstatus}

Die "Seriousness of Illness Rating Scale" van Wyler, Masuda en Holmes (1968) is gebruik om gesondheidstatus van die respondente te bepaal. Die vraelys bestaan uit 'n 126itemskaal waarin die mees algemene fisieke en geestesiektes en simptome gelys word. Met die ontwikkeling van die skaal is ' $\mathrm{n}$ algemene ernstigheidsgraad aan elke siekte/ simptoom toegeken, deur van mediese dokters en die algemene publiek gebruik te maak. Die skaal lys hiervolgens siektes/simptome wat strek vanaf 1 tot 126. Die gradering van die ernstigheid reflekteer die prognose, duur, lewensbedreiging, graad van ongeskiktheid en graad van ongemak wat as gevolg van die siekte/simptoom ervaar word. Omvattende navorsing is alreeds met hierdie siektegraderingskaal gedoen (Kobasa, Maddi, Pucetti \& Zola, 1985; Rosenberg, Hayes \& Peterson, 1987; Wise, Mann, Puscheck, Dove \& Kiernan, 1985).

\section{Uitbranding}

Die uitbrandingvraelys is saamgestel deur Pines, Aronson en Kafry (1981). Dit is 'n 21-itemvraelys wat beantwoord kan word deur 'n waarde (1-7) aan elke vraag toe te ken, met $1=$ nooit en $7=$ altyd. Die 21 vrae meet fisiese, emosionele en kognitiewe uitputting. Volgens Pines et al., (1981) is die Pines-uitbrandingskaal betroubaar (Cronbach-alfa-betroubaarheidswaarde $=0.81$ ) en besit 'n interne konstantheid, soos bereken met die Alpha-koëffisiënt van 0.91-0.93. ' $n$ Betroubaarheidskoëffisiënt van 0.89 (eerste maand), $0.76 \leq$ tweede maand) en 0.66 (vierde maand) is onderskeidelik, gevind. ' $\mathrm{n}$ Beduidende korrelasie met 'n waarskynlikheidswaarde van p (0.05 is tussen die uitbrandingskaal, werk- en lewensdruk gevind (Diedericks, 1996).

\section{Statistiese ontleding}

Die CSS:Statistica rekenaarpakket wat op die Potchefstroomse Universiteit vir Christelike Hoër Onderwys (PU vir CHO) se netwerk beskikbaar is, is gebruik om die data te verwerk. Met behulp van ' $n$ eenrigtingvariansie-analise is bepaal of uitbranding ' $n$ verband met gesondheidstatus vertoon. 'n Tweerigtingvariansie-analise is gebruik om fisieke aktiwiteit se effek op die verband van uitbranding met gesondheidstatus te bepaal. In gevalle waar statisties betekenisvolle verskille voorgekom het, is die Newman-Keuls post hoctoets (Thomas en Nelson, 1990) gebruik om te bepaal watter groepe betekenisvol van mekaar verskil. Laastens is die praktiese betekenisvolheid van verskille tussen groepe bereken deur van Cohen se effekgrootte (Thomas en Nelson, 1990) gebruik te maak.

\section{RESULTATE EN BESPREKING}

Die gemiddelde ouderdom van die respondente $(\mathrm{N}=278)$ wat in die ondersoek gebruik is, was $37.97 \pm 9.18$, met die jongste respondent 20 jaar en die oudste respondent 60 jaar. Die respondente was jonger as 'n groep vrouens $(\mathrm{N}=70)$ wat in ' $\mathrm{n}$ studie deur Rabie (1999) gebruik is (45.53 \pm 1 3.23). Die gemiddelde deelname aan fisieke aktiwiteit, soos bepaal met die fisieke aktiwiteitsindeks (FAI) van Sharkey (1984), was $24.70 \pm 31.71$. Dit is hoër as ' $n$ gemiddelde waarde wat verkry is deur Rabie (1999) vir 70 blanke vrouens, naamlik 16.33(28.43 en ook as $18.12 \pm 25.23$, wat verkry is deur Van der Merwe (1998) in 'n studie op 525 blanke mans. Gesondheidstatus wat aangedui word met die Siektegraderingskaal (SGS) van Wyler et al. (1968) se gemiddelde waarde was $245.59 \pm 171.90$. Díe waarde is laer as die waarde wat deur Van der Merwe (1998) by 'n groep manlike respondente verkry is, naamlik $258.84 \pm 188.27$.

\section{TABEL 1}

BESKRYWENDE STATISTIEK VAN IN GROEP VROULIKE BESTUURSLUI ( $\mathbf{N}=278)$ - SANGALA-STUDIE

\begin{tabular}{lllll}
\hline Parameter & $\overline{\boldsymbol{x}} \overline{\mathbf{x}}$ & MIN & MAKS & S.A. \\
\hline Ouderdom & 37.97 & 20.00 & 60.00 & 9.18 \\
FAI & 24.70 & 0.00 & 164.00 & 31.71 \\
SGS & 245.59 & 0.00 & 961.00 & 171.90 \\
Uitbranding & 3.13 & 1.10 & 5.71 & 0.78 \\
Belloc \& Breslow & 4.06 & 0.00 & 7.00 & 1.61 \\
\hline $\bar{x} \bar{x}=$ gemiddelde waarde & S.A. = standaardafwyking & \\
MIN = minimumwaarde & FAI = fisieke aktiwiteitsindeks & \\
MAKS = maksimumwaarde & SGS = siektegraderingskaal &
\end{tabular}

Die oorgrote meerderheid van die dames was blank, naamlik $85.4 \%$ terwyl $13.5 \%$ bestaan het uit swart vrouens, $0.7 \%$ uit Kleurlinge en $0.4 \%$ uit Potugese vrouens. Fisieke aktiwiteit moet aan sekere inoefeningsbeginsels ten opsigte van intensiteit, duur en frekwensie van deelname voldoen. Die Amercan College for Sports Medicine (ACSM) (1995) beveel ' $n$ intensiteit van $60 \%-90 \%$ van die maksimale harttempo, 'n frekwensie van 3-5 maal per week en ' $n$ duur van 20-30 minute per oefensessie aan. Hierdie oefeningsvereistes is nodig alvorens fisieke aktiwiteit enige gesondheids-konserverende of terapeutiese waarde kan hê (Pollock, Wilmore \& Fox, 1984). Wanneer die voorvereistes vir fisieke aktiwiteit gekwantifiseer word deur van die indeks van Sharkey (1984) gebruik te maak, sal dit ' $n$ indeks van 36 beteken. Die meerderheid van die respondente (68\%) het 'n fisieke-aktiwiteitsindeks van kleiner as 36 vertoon terwyl slegs 32\% van die respondente ' $n$ fisieke-aktiwiteitsindeks gehad het wat groter is as 36. Die proefgroep was dus relatief fisiek onaktief. Die rede vir die verlaagde deelname aan fisieke aktiwiteit is moontlik die min tyd om te oefen as gevolg van die aard van die werk. Strydom et al. (1991) toon aan dat dames tussen die ouderdom 35 en 64 jaar die minste aktief is van al die onderskeie ouderdomsgroepe (10-65 jaar).

Soos aangedui in Figuur 1 rapporteer $44.8 \%$ van die respondente ligte uitbranding. Die meerderheid van die respondente $(55.2 \%)$ ervaar onderskeidelik matige (44\%) en ernstige (11.2\%) uitbranding.

Uitbranding, soos bepaal met behulp van die uitbrandingvraelys van Pines et al. (1981), toon in die literatuur negatiewe verbande met verskeie psigologiese en emosionele 
aspekte by ' $\mathrm{n}$ verskeidenheid tipe respondente. Weisberg en Sagie (1999) vind in ' $n$ studie op 28 onderwyseresse dat beide fisiese en kognitiewe uitbranding ' $n$ betekenisvolle invloed gehad het op die onderwyseresse se behoefte om te bedank. Uitbranding kan ook by vrouens voorkom wanneer hulle voel hulle lewe net 'n rol en/ of wanneer hulle voel hulle lewer nie ' $n$ betekenisvolle bydrae tot medewerkers of die gemeenskap nie, aldus Pines en Guendelman (1995). Simptome van koronêre hartvatsiektes word ook gekoppel aan episodes van hoë subjektiewe stres en spanning (Kinne, Droste, Fahrenberg \& Roskamm, 1999). Oormatige kardiovaskulêre response op chroniese stres kan ook lei tot die ontwikkeling van hipertensie en koronêre hartvatsiektes, aldus Weidner en Messina (1998). Louw en Edwards (1993) vind dat stres ' $n$ negatiewe invloed op die immuunsisteem van die liggaam het. Die liggaam se vermoë om homself teen infeksies en siektes te beskerm neem af soos wat episodes van ernstige stres of uitbranding toeneem. Daar kan dus verwag word dat die voorkoms van siektes sal toeneem soos die mate van uitbranding toeneem. Vervolgens ' $n$ bespreking van die eenrigting-variansieanalise waarin uitbranding se verband met gesondheidstatus bestudeer is.

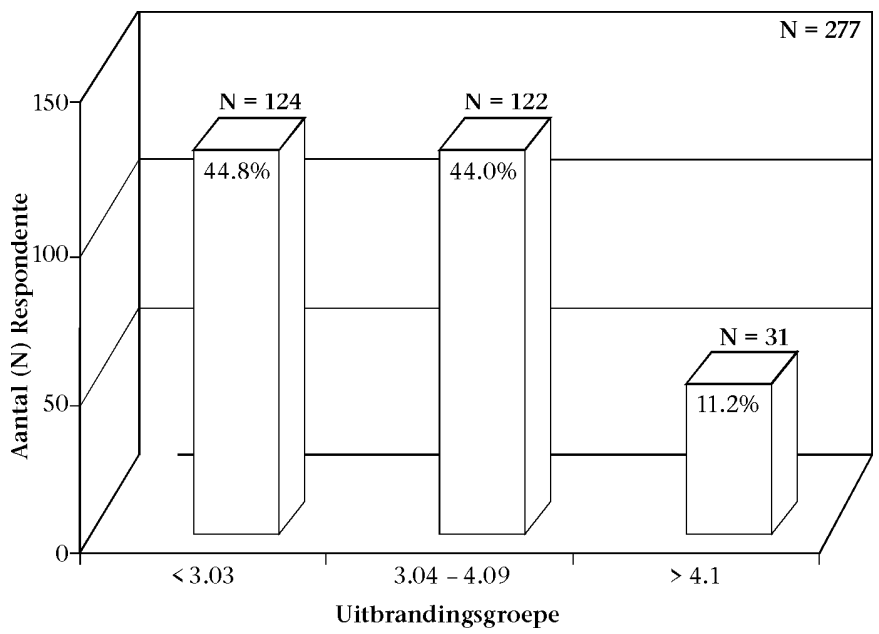

Figuur 1: Die voorkoms van uitbranding by vroulike bestuurslui

Uitbranding se verband met gesondheidstatus soos ondersoek met ' $n$ eenrigtingvariansie-analise

Vir die doel van die analise is die respondente in drie groepe verdeel volgens die mate van uitbranding. Die indeling is gedoen volgens die grense soos gestel deur Pines et al. (1981). ' $n$ Waarde van $\leq 3.09$ dui op lae uitbranding, 3.10-4.09 dui op matige uitbranding en $\geq 4.1$ op uitbranding in ' $n$ ernstige graad. Volgens die eenrigtingvariansie-analise het statisties betekenisvolle $\leq$ $\mathrm{p}(0.05)$ verskille ten opsigte van gesondheidstatus (soos bepaal deur die siektegraderingskaal van Wyler et al., 1968) by die respondente voorgekom. Die Newman-Keuls post hoc-toets het aangetoon dat die gesondheidstatus van die respondente in al drie die uitbrandingsgroepe statisties betekenisvol $\mathrm{p} \leq 0.05$ ) van mekaar verskil het. Matig prakties betekenisvolle verskille ( $\mathrm{EG} \geq 0.5$ ) het ook tussen groepe (b) en (c) voorgekom, asook hoog prakties betekenisvolle verskille $(E G \geq 0.8)$ tussen groepe (a) en (c). Dit is duidelik uit die studie dat hoe minder uitbranding die respondente ervaar het, hoe beter staat van gesondheid het hulle vertoon.
TABEL 2

UITBRANDING SE VERBAND MET GESONDHEIDSTATUS BY VROULIKE BESTUURSLUI

\begin{tabular}{|c|c|c|c|c|c|c|c|c|c|}
\hline \multicolumn{10}{|c|}{ Uitbranding } \\
\hline \multicolumn{4}{|c|}{ Laag (3.09) } & \multicolumn{3}{|c|}{ Matig (3.10-4.09) } & \multicolumn{3}{|c|}{ Hoog (4.10) } \\
\hline Parameter & $\mathrm{N}$ & $\bar{x}$ & S.A. & $\mathrm{N}$ & $\bar{x}$ & S.A. & $\mathrm{N}$ & $\bar{x}$ & S.A. \\
\hline SGS & 134 & a) $201,88^{\mathrm{B}, \mathrm{C}^{*}}$ & 151.13 & 107 & b) $265.47^{a, c+}$ & 176.98 & 33 & c) $362.88^{a^{*}, b^{+}}$ & 173.79 \\
\hline \multicolumn{5}{|c|}{$\mathrm{N}=$ aantal respondente } & \multicolumn{5}{|c|}{$* * *=\mathrm{p} \leq 0.05$} \\
\hline \multicolumn{5}{|c|}{$\bar{x} \bar{x}=$ gemiddelde waarde } & \multicolumn{5}{|c|}{$\begin{array}{l}\text { S.A. = standaardafwyking } \\
\text { SGS }=\text { siektegraderingskaal }\end{array}$} \\
\hline \multicolumn{10}{|c|}{$+=$ matig prakties betekenisvolle verskille $(\mathrm{EG} \geq 0.5$ ) } \\
\hline \multicolumn{10}{|c|}{${ }^{*}=$ hoog prakties betekenisvolle verskille $(\mathrm{EG} \geq 0.8)$} \\
\hline
\end{tabular}

Die vraag het nou ontstaan of fisieke aktiwiteit enige invloed het op die bogenoemde verband wat uitbranding met gesondgheidstatus vertoon. Vervolgens is ' $n$ tweerigtingvariansie-analise gedoen waarin FAI en uitbranding se verbande met gesondheidstatus bestudeer is. Vir die doel van die analise is die respondente ten opsigte van deelname aan fisieke aktiwiteit in twee groepe verdeel, naamlik ' $n$ fisiek onaktiewe (FAI $\leq 44)$ en ' $n$ fisiek aktiewe (FAI $\geq 45$ ) groep. Díe resultate van die analise word aangedui in Tabel 3 en Figuur 2. Die onaktiewe respondente met ' $n$ lae uitbrandingsvlak (groep a) het statisties betekenisvol verskil $(\mathrm{p} \leq 0.05)$ van die fisiek onaktiewe respondente met 'n hoë uitbrandingsyfer (groep e). Die verskille was ook hoog prakties betekenisvol $(\mathrm{EG} \geq 0.8$ ). Verder het die fisiek aktiewe respondente met ' $n$ lae uitbrandingsyfer (groep b) ook statisties betekenisvol verskil van die fisiek onaktiewe respondente met 'n hoë uitbrandingsyfer (groep e). Díe verskille was ook hoog prakties betekenisvol ( $\mathrm{EG} \geq 0.8)$.

TABeL3

DIE GESAMENTLIKE EN ONAFHANKLIKE VERBANDE VAN UITBRANDING EN FISIEKE AKTIWITEIT MET DIE GESONDHEIDSTATUS VAN VROULIKE BESTUURSLUI

\begin{tabular}{|c|c|c|c|c|c|c|c|c|c|}
\hline \multicolumn{10}{|c|}{ Uitbranding } \\
\hline \multicolumn{4}{|c|}{ Laag (3.09) } & \multicolumn{3}{|c|}{ Matig (3.10-4.09) } & \multicolumn{3}{|c|}{ Hoog (4.10) } \\
\hline Parameter & $\mathrm{N}$ & $\bar{x}$ & S.A. & $\mathrm{N}$ & $\bar{x}$ & S.A. & $\mathrm{N}$ & $\bar{x}$ & S.A. \\
\hline SGS Onaktief & 96 & a) $201,76 \mathrm{e}^{*}$ & 150.53 & 93 & c) 265.00 & 180.38 & 28 & e) $373.79 \mathrm{a}^{\star}, \mathrm{b}^{\star}$ & 182.43 \\
\hline Aktief & 38 & b) $202.18 \mathrm{e}^{*}$ & 154.69 & 14 & d) 268.41 & 158.41 & 5 & f) 301.80 & 207.20 \\
\hline \multicolumn{4}{|c|}{$\mathrm{N}=$ aantal respondente } & \multicolumn{3}{|c|}{$* * *=p \leq 0.05$} & & & \\
\hline \multicolumn{4}{|c|}{$\bar{x} \overline{\mathrm{X}}=$ gemiddelde waarde } & \multicolumn{5}{|c|}{$\begin{array}{l}\text { S.A. = standaardafwyking } \\
\text { SGS }=\text { siektegraderingskaal }\end{array}$} & \\
\hline \multicolumn{10}{|c|}{$+=$ matig-prakties betekenisvolle verskille $(\mathrm{EG} \geq 0.5)$} \\
\hline \multicolumn{10}{|c|}{${ }^{*}=$ hoog-prakties betekenisvolle verskille $(\mathrm{EG} \geq 0.8)$} \\
\hline
\end{tabular}

Statisties betekenisvolle ( $\mathrm{p} \leq 0.05$ ) verskille tussen die 6 groepe soos bepaal met die Newman-Keuls post hoc-toets word met die alfabetiese kodes a, b, c, $\mathrm{d}$ en e langs die gemiddelde waardes aangedui.

Dit blyk verder uit Tabel 3 en Figuur 2 dat fisieke aktiwiteit geen effek het op die negatiewe verband wat uitbranding met gesondheidstatus vertoon nie. Verskeie redes kan hiervoor aangevoer word. Dit is moontlik dat die vlak van deelname aan fisieke aktiwiteit te laag of onvoldoende was of dat oefening 
nie die oplossing is vir ' $\mathrm{n}$ persoon wat reeds aan uitbranding ly nie. 'n Ander interessante verskynsel is die aantal respondente in groepe (d) en (f), naamlik 14 in groep d en 5 in groep f, wat waarskynlik ' $n$ invloed op die resultate het. Min respondente met matige en ernstige uitbranding was dus fisiek aktief. Dit is nie totaal onmoontlik dat die respondente in groepe $d$ en $f$ mense is wat relatief onlangs (minder as 3 maande) eers begin oefen het nie. Groepe d en $\mathrm{f}$ kan dus volgens so ' $\mathrm{n}$ argument bestaan uit 'n seleksie van individue wat nog nie lank genoeg oefen sodat die oefening enige betekenisvolle effek op hulle psigologiese welstand kon gehad het nie. Daar is egter verskeie verskynsels in Figuur 2 wat daarop dui dat laasgenoemde argument 'n onwaarskynlike verklaring vir die resultate in Figuur 2 is.

Uitbranding is ' $\mathrm{n}$ produk van ' $\mathrm{n}$ persoon se lewensfilosofie (Pines, 1993). Pines (1994) het in 'n studie op 159 respondente gevind dat mense nie uitbrand wanneer hulle bestaanswaarde ervaar in die take wat hulle verrig nie. In 'n studie op 100 werkers met ' $n$ gemiddelde ouderdom van 49 jaar toon Wright en Bonett (1997) dat daar ' $n$ negatiewe verband tussen emosionele uitputting en werksprestasie bestaan. Die verband het voorgekom onafhanklik van aspekte soos ouderdom, geslag en aanvangs- werkprestasiewaardes. Volgens Pines (1993) is die hoofoorsaak van uitbranding wanneer 'n persoon lewenssinvolheid deur middel van sy werk probeer verkry en nie daarin slaag nie. ' $\mathrm{n}$ Mens kan nie verwag dat deelname aan fisieke aktiwiteit 'n invloed sal hê op aspekte soos lewensfilosofie, lewenswaardes, persoonlike normes en reëls wat alles rolspelers met betrekking tot uitbranding en ' $n$ gevoel van bestaanswaarde is.

Die fisiek onaktiewe respondente met lae uitbranding toon duidelik beter vlakke van gesondheid as die fisiek aktiewe respondente met hoë uitbranding (vergelyk groepe a en $\mathrm{f}$ Figuur 2 en Tabel 3). Dit is verder interessant en insiggewend dat groepe a en b bymekaar gegroepeer was (Figuur 2) ten opsigte van gemiddelde gesondheidstatuswaardes. Eweneens was groepe d en c bymekaar gegroepeer maar met duidelik swakker gesondheidsprofiele as groepe a en b. Fisieke aktiwiteit het dus by beide die respondente met lae uitbranding en matige uitbranding geen effek op die respondente se gesondheid nie. Emosionele uitputting of uitbranding toon aan die ander kant 'n lynregte verband met gesondheidstatus. Hoër vlakke van uitbranding het onafhanklik van fisieke aktiwiteit met swakker gesondheidstatuswaardes, gepaard gegaan. Die insiggewenste verskynsel in Figuur 2 is egter dat die fisiek onaktiewe respondente met lae en matige uitbranding (groepe a en c) beter gesondheidstatusprofiele vertoon het as die hoog aktiewe respondente met hoë uitbranding (groep f - Figuur 2).

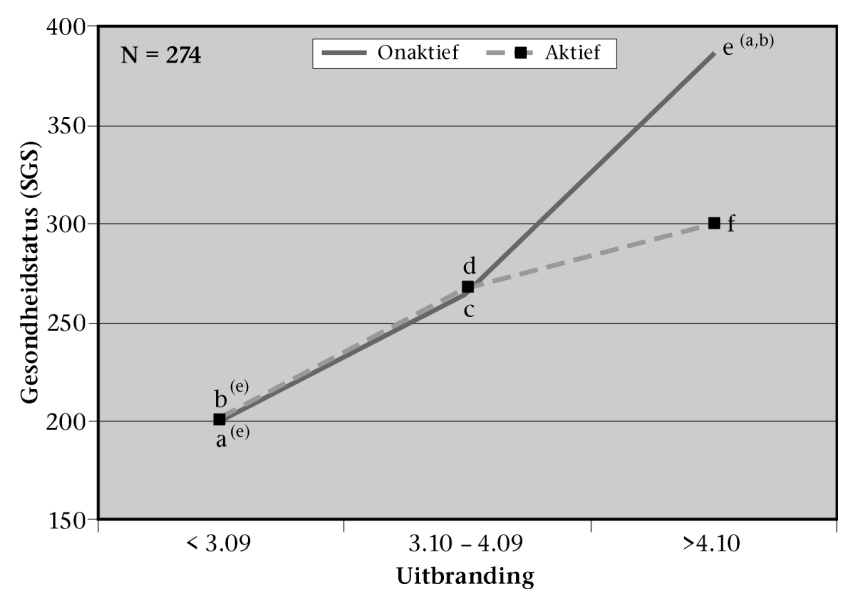

Figuur 2: Fisieke aktiwiteit en uitbranding se verbande met gesondheidstatus by vroulike bestuurslui
Duidelik dus dat fisieke aktiwiteit nie die effek van persoonlike waardes, reëls, norme en lewensuitkyk op gesondheid neutraliseer nie. Dit wil ook voorkom of hierdie aspekte (lewensuitkyk, persoonlike waardes, reëls en norme asook 'n gevoel van bestaanswaarde) belangriker is ten opsigte van gesondheid by hierdie groep vroulike bestuurslui as deelname aan fisieke aktiwiteit. By die respondente met hoë uitbranding (groepe e en f) het die fisiek aktiewe respondente (groep f) wel beter gesondheidstatusprofiele vertoon as die fisiek onaktiewe respondente (groep e). Die verskil was nie statisties betekenisvol $(\mathrm{p}>0.05)$ nie waarskynlik as gevolg van die min respondente in groep e $(n=5)$. By die repondente met hoë uitbranding lyk dit dus of fisieke aktiwiteit bepaalde voordele met betrekking tot gesondheidstatus vir die respondente tot gevolg gehad het.

In ' $\mathrm{n}$ studie op 70 blanke dames wat op 'n fisieke inoefeningsprogram van 12 maande geplaas was, vind Rabie (1999) dat die inoefening ' $n$ positiewe effek op die respondente se psigologiese welstand gehad het. Hierdie aanpassing in die studie van Rabie (1999), het plaasgevind onafhanklik van faktore soos ligaamsmassa-verlies en sonder dat enige intervensie met betrekking tot lewensuitkyk, lewenswaardes en norme gedoen is.

'n Faktor wat moontlik 'n invloed kon hê op laasgenoemde resultate is hormonale veranderinge (afskeiding van endorfiene en katesjolamiene) wat plaasvind direk na deelname aan 'n aërobiese oefensessie (Falkenberg, 1987). Dit kan daartoe aanleiding gee dat individue laer angs en stres ervaar, kognitiewe take makliker verrig en gevolglik beter oor hulself en hul omstandighede voel. Pretorius et al. (1989) vind dat stresgeneigde persone andersoortige response ten opsigte van prolaktien-, kortisol- en testosteroonvlakke na ' $n$ inoefenings-periode van drie maande tydens ' $n$ fisieke en kognitiewe stressituasie vertoon, as 'n ongeoefende kontrolegroep. Die hormoonresponse dui daarop dat die geoefende groep die stressituasie as 'n uitdaging ervaar het, terwyl die ongeoefende groep se hormoonsekresie daarop dui dat hulle dit as ' $n$ bedreiging beskou het (Pretorius et al., 1989).

In beide die studies van Rabie (1999) en Pretorius et al. (1989) is daar nie gekorrigeer vir aanvangswaardes van stres of lewensgeluk nie. Dit kan 'n groot invloed op die resultate hê. Volgens Dreyer (1999) verdwyn die invloed van fisieke aktiwiteit grootliks sodra daar vir die aanvangswaardes van uitbranding en lewensgeluk gekorrigeer word. Fisieke aktiwiteit het in die studie (Dreyer, 1999) die lewensgeluk van respondente met lae aanvangswaardes, statisties betekenisvol verbeter. Die interessante verskynsel was egter dat fisieke aktiwiteit nie die lewensgeluk en psigologiese wel-standwaardes gelig het tot op dieselfde vlak as die van die respondente wat by aanvang hoog was nie. Die resultate soos aangebied in Figuur 2 reflekteer dieselfde verskynsel maar in hierdie geval met betrekking tot gesondheid. In die hoë uitbrandingsgroep vertoon die fisiek aktiewe respondente beter gesondheidstatuswaardes as die fisiek onktiewes. Die fisiek aktiewes met hoë uitbranding (groep f) toon egter nie 'n beter gesondheidsprofiel as die fisiek onaktiewes met lae en matige uitbranding nie (groepe a en c). Nadat daar dus vir uitbranding gekorrigeer is het fisieke aktiwiteit nie werklik in hierdie studie gepaard gegaan met beter gesondheid nie. Fisieke aktiwiteit het in kort nie die negatiewe effek van emosionele uitputting op gesondheid totaal oorbrug of geneutraliseer nie.

\section{GEVOLGTREKKING}

Die resultate van die studie dui daarop dat uitbranding 'n statisties betekenisvolle verband $(p(0.05)$ met die 
gesondheidstatus van vroulike bestuurslui toon. By die respondente met hoë uitbranding het die fisiek aktiewe respondente beter gesondheidstatusprofiele vertoon as die fisiek onaktiewe respondente. By die respondente met hoë uitbranding lyk dit dus of fisieke aktiwiteit bepaalde voordele met betrekking tot gesondheidstatus vir die respondente tot gevolg gehad het. Fisieke aktiwiteit het egter in hierdie studie nie die negatiewe effek van emosionele uitputting op die gesondheid van vroulike bestuurslui totaal geneutraliseer nie.

\section{VERWYSINGS}

ACSM'S Guidelines for exercise testing and prescription. (1995). 5th ed. American College of Sports Medicine: Williams \& Wilkens.

Aldana, S.G., Sutton, L. D., Jacobson, B. H. \& Quirk, M. G. (1996). Relationships between leisure time physical activity and perceived stress. Perceptual and Motor Skills, 82 (1), 315-321.

Ardell, D.A. (1986). High level wellness: an alternative to doctors, drugs and disease. Berkeley, Calif.: Ten speed.

Baun, W.B., Bernacki, E.J. \& Tsai, S.P. (1986). A preliminary investigation: Effect of a corporate fitness program on absenteeism and health care cost. Journal of Occupational Medicine, 28, 18-22.

Beehr, T.A. (1978). Job stress, employee health and organizational effectiveness: a facet analysis, model and literature review. Personnel Psychology, 31, 665-699.

Berger, B.G. (1996). Psychological benefits of an active lifestyle: what we know and what we need to know. Quest, 48 (3), 331-353.

Blair, S.N., Horton, E., Leon, A. S., Lee, I., Drinkwater, B. L., Dishman, R. K., Moakey, M. \& Kienholz, M. L. (1996). Physical activity, nutrition and chronic disease. Medicine and Science in Sports and Exercise, 28 (3), 335-344.

Bly, J., Jones, R., \& Richardson, T. (1986). Impact of worksite health promotion on health care costs and utilization: Evaluation of Johnson and Johnson's live for life program. Journal of the American Medical Association, 256, 3235-3240.

Bouchard, C. \& Despres, J. (1995). Physical activity and health: atherosclerotic, metabolic and hypertensive diseases. Research Quarterly for Exercise and Sport, 66 (4), 268-275.

Dickman, S.R. (1988). Pathways to wellness. Champaign, Ill.: Life Enhancement.

Diedericks, J.C. (1996). Die verwantskap van sin vir koherensie met werkstres, algemene gesondheid en sielkundige uitbranding by bestuurders. Ongepubliseerde M.Comm verhandeling. Universiteit van Suid Afrika.

Dreyer, L.I. (1991). Fisieke aktiwiteit, fisieke werksvermöe en enkele morfologiese, fosiologiese en biochemiese parameters by uitvoerende amptenare. Ongepubliseerde M.A.-verhandeling. PU vir CHO. Potchefstroom.

Dreyer, L.I. (1996). Totale welstand: 'n begripsomskrywing. $2^{\text {de }}$ uitg. Johannes van der Walt - Instituut vir Biokinetika. Departement Menslike Bewegingskunde. PU vir CHO. Potchefstroom.

Dreyer, L.I. (1999). Physical activity and health: protection or self-selection? (Paper delivered on 8-10 September 1999 as part of the All Africa Pre-Games Scientific Congress.) Johannesburg.

Falkenberg, L.E. (1987). Employee fitness programs: Their impact on the employee and the organization. The Academy of Management Review, 12 (3), 511-522.

Jordaan, R. (1998). Fisieke aktiwiteit en enkele lewenstylaspekte as bepalers van gesondheid. Ongepubliseerde M.A.-skripsie. PU vir CHO. Potchefstroom.
Kinne, G., Droste, C., Fahrenberg, J. \& Roskamm, H. (1999). Symptomatic myocardial ischemia and everyday life: Implications for clinical use of intractive monitoring. Journal of Psychosomatic Research, 46 (4), 369-377.

Kobasa, S.C., Maddi, S.R., Pucetti, M.C. \& Zola, M.A. (1985). Effectiveness of hardiness, exercise and social support as resources against illness. Journal of Psychosomatic Research, 29 (5), 525-533.

Louw, D.A. \& Edwards, D.J.A. (1993). Sielkunde: ' $n$ handleiding vir studente in Suider-Afrika. Isando: Lexicon.

Maslach, C. \& Jackson, S.E. (1981). The measurement of experienced burnout. Journal of Occupational Behavior, 2, 99-113.

Massie, B.M. (1992). To combat hypertension, increase activity. The Physician and Sportsmedicine, 20 (5), 89-108.

Pines, A.M., Aronson, E. \& Kafry, D. (1981). Burnout: from tedium to personal growth. New York: Free Press.

Pines, A.M. (1994). The palestinian intifada and Israelis' burnout. Journal of Cross Cultural Psychology, 25 (4), 438-451.

Pines, A. \& Guedelman, S. (1995). Exploring the relevance of burnout to Mexican blue collar woman. Journal of Vocational Behavior, 47(1), 1-20.

Pines, A.M. (1993). Burnout: An existential perspective. Washington, DC.: Taylor \& Francis.

Plowman, S.A. (1992). Physical activity, physical fitness and low back pain. Exercise and Sport Sciences Reviews, 20, 221242.

Pollock, M.L., Wilmore, J.H. \& Fox. S.M. (1984). Exercise in health and disease: evaluation and prescription for prevention and rehabilitation. Philadelphia: W. B. Saunders.

Pretorius, P.J., Malan, N.T., Strydom, G.L., Eloff, F.C., Laubscher, P.J., Huisman. H.W., De Klerk, F.A. J., Van Der Merwe, J.S. (1989). Occupational stress as a risk factor in ischaemic heart disease with specific reference to the development of appropriate intervention programs. PU for $\mathrm{CHE}$. Potchefstroom.

Rabie, P. (1999). Die invloed van fisieke inoefening op geestellike welstand van dames. Ongepubliseerde M.A.-skripsie. PU vir CHO. Potchefstroom.

Robbins, G., Powers, D. \& Burgess, S. (1991). A wellness way of life. Wim. C. Brown Publishers.

Rosenberg, S.J., Hayes, J.R. \& Peterson, R.A. (1987). Revising the seriousness of illness rating scale: modernization and restandardization. International Journal of Psychiatry in Medicine, 17 (1), 85-92.

Selye, H. (1956). The stress of life. New York: McGraw-Hill.

Sharkey, B.F. (1984). Physiology of fitness. Champaign, Ill: Human Kinetics.

Shephard, R.J. (1997). Exercise and relaxation in health promotion. Sports Medicine, 23 (4), 211-217.

Strümpfer, D.J.W. (1982). Executive dystress, executive eustress, and what makes the difference. Johannesburg. (Inaugural lecture, 27Jul). University of the Witwatersrand.

Strydom, G.L., Kotze, J.P., Roux, F.G., Scoeman, J.J., Joubert, L.J., Van Der Merwe, A.M., Van Der Westhuizen, D.C. \& Dreyer, L.I. (1991). Die fisieke aktiwiteitsprofiel van S. A. blankes (mans en dames, 10-64 jaar) in enkele Transvaalse stede (VIGOR-studie). Suid-Afrikaanse Tydskrif vir Navorsing in Sport, Liggaamlike Opvoedkunde en Ontspanning, 14 (2), 65-76.

Strydom, G.L. \& Dreyer, L.I. (1991). Van fisieke fiksheid na totale welstand. Instituut vir Biokinetika. $\mathrm{PU}$ vir $\mathrm{CHO}$. Potchefstroom.

Thomas, J.R. \& Nelson, J.K. (1990).. Research methods in physical activity, $2^{\text {nd }}$. ed. Champaign, Ill.: Human Kinetics.

Van Der Merwe, S. (1995). Fisieke aktiwiteit en geestelike welstand van blanke mans in Potchefstroom. Ongepubliseerde M.A.verhandeling. PU vir CHO. Potchefstroom.

Van Der Merwe, G.G. (1998). Fisieke aktiwiteit, lewenstyl en enkele 
sosio-ekonomiese aspekte se verband met die gesondheidstatus van mans. Ongepubliseerde M.Sc-skripsie. PU vir CHO. Potchefstroom.

Weidner, G. \& Messina, C.R. (1998). Cardiovascular reactivity to mental stress. USA: Lawrence Erlbaun Associates. 298p.

Weisberg, J. \& Sagie, A. (1999). Teachers' physical, mental, and emotional burnout: impact on intention to quit. Journal of Psychology, 133 (3), 333-339.

Wise, T.M., Mann, L.S., Puscheck, E., Dove, H. \& Kiernan, K.
(1985). Factor affecting anxiety and depression in psychiatric consultation patients. International Journal of Psychiatry in Medicine, 15 (2), 177-184.

Wright, T.A. \& Bonnett, D.G. (1997). The contribution of burnout to work performance. Journal of Organizational Behavior, 18, 491-499.

Wyler. A.R., Masuda. M. \& Holmes, T.H. (1968). Seriousness of illness rating scale. Journal of Psychosomatic Research, 11, 363-374. 